\title{
Emprego de Sistema de Informações Geográficas (SIG) na Modelagem e Monitoramento de um Campus Universitário
}

\author{
Geographic Information Systems (GIS) applied to an University Campus modeling and monitoring
}

\author{
> Fernando Rodrigues Lima \\ Universidade Federal do Rio de Janeiro, Brazil \\ frlima@poli.ufrj.br
}

> Emanuel Filipe de Alarcão Melo de Moraes

Universidade Federal do Rio de Janeiro, Brazil

efamm08@poli.ufrj.br

\author{
> Patricia Estevão dos Santos \\ Universidade Federal do Rio de Janeiro, Brazil \\ patriciaestevao@poli.ufrj.br
}

\begin{abstract}
This paper presents a research on GIS to organize the available data from infrastructure and facilities in a University campus. It integrates and compiles a range of data under ontology that will permit the enhancement of geographic database regarding monitoring and control systems. The team worked with campus administration using desktop hardware and software to consolidate information about water, sewage, energy and other networks at backbone scale. The boundaries of buildings, parking, streets and land use were also included. The geographic features and tables assigned are intended to work under WebGIS, mobile device, participative platforms, BIM structures and 3D simulation.
\end{abstract}

Keywords: GIS; Digital graphic modeling; Urban engineering; University campus.

\section{Introdução}

As plataformas SIG apresentam-se como um ferramental altamente apropriado ao registro, consulta e edição de informaçóes relacionadas a um campus universitário. Todo este potencial é viabilizado pela própria arquitetura de um ambiente SIG, que permite associar a representação gráfica digital (feiçóes geográficas) aos dados tabulares (planilhas), contemplando temas tão diversos quanto a infraestrutura urbana e a gestáo acadêmica. No momento atual procura-se empregar conceitos de sustentabilidade em todos os níveis de vivência da sociedade, e o SIG pode ser utilizado como recurso importante na consolidaçáo deste objetivo pelos gestores do sítio universitário (Couto, 2012).

A modelagem digital de um campus permite não só visualizar e entender a sua complexidade intrínseca, mas também prover informaçóes que auxiliem na exploração de cenários possíveis e tomada de decisão por estes gestores. As universidades oferecem um vasto potencial para o desenvolvimento e implantação de redes e tecnologias sustentáveis (Konig, 2013), mas sem os instrumentos que potencializem esta tarefa - que pressupóe informação e integração - as possiblidades de validação do experimento e sua replicação no meio externo podem estar seriamente comprometidas.

O campus universitário em questão está situado em uma ilha com cerca de 5,5 milhóes de metros quadrados, originada a partir do aterro de 8 ilhas existentes, e abriga não somente a universidade, mas também centros de pesquisa, polos, empresas e incubadoras de tecnologia. Isto lhe confere a escala de um bairro, com alta demanda de infraestrutura e uma enorme populaçáo flutuante. Embora próximo de áreas importantes (aeroporto, centro financeiro, etc.) e das redes de mobilidade, o campus ainda é pouco integrado com a cidade que o cerca. Por outro lado, a maioria de suas instalaçóes data de 1950, apresentam alto grau de obsolescência e, portanto uma oportunidade impar para se pensar na ampliação e renovação de suas edificaçóes e sistemas de infraestrutura.

Dentro do contexto aqui exposto, o presente artigo relata o desenvolvimento de uma base geográfica voltada para representaçáo e organizaçáo de dados no campus desta universidade brasileira. As características adotadas para a modelagem digital contida nesta base SIG objetivam promover uma maior interação entre os usuários e gestores do campus, motivando-os na busca por uma maior integração com o restante da cidade, pela obtenção de indicadores mais eficientes, pela inovação em suas redes de serviço e infraestrutura e, principalmente: abrindo um novo horizonte operacional para o desenvolvimento das atividades de ensino, pesquisa e extensão.

\section{Metodologia}

A metodologia adotada foi derivada de métodos e técnicas anteriormente desenvolvidos para a representação de cidades no âmbito de nossa pesquisa em Engenharia Urbana. O trabalho é inédito no contexto desta universidade, tratando-se, portanto, da primeira abordagem institucional direcionada para a elaboração de bases em SIG. Destacamos que os resultados produzidos poderão ser facilmente exportados e integrados em outros sistemas SIG, sejam aportados em softwares livres ou proprietários. 
É importante deixar claro que o objetivo desta pesquisa foi viabilizar a aquisição, análise, compilação e tratamento dos dados obtidos, convertendo-os para um ambiente SIG que permitisse a terceiros utilizá-lo na posterior implantação de plataformas colaborativas, sistemas de vigilância e controle, manutenção de instalaçôes, etc. Notadamente, a tarefa de gestão de sistemas é domínio de especialistas, porém um conhecimento básico de conceitos e aplicaçôes que pesquisamos nesta área nos permitiu conceber um SIG mais aderente às rotinas que lhe poderão ser demandadas futuramente.

Em um primeiro momento foram identificados e consultados os principais atores que objetivam a busca local por açôes e práticas sustentáveis: a prefeitura do campus, o gestor do fundo de sustentabilidade e os gestores acadêmicos e de infraestrutura. Em seguida foi definida uma plataforma desktop que possibilitasse a posterior transferência da base de dados elaborada para um WebSIG. Foi utilizado o software ArcGIS Desktop v10.1 e sua extensão ArcScenel 3DAnalist. A opção foi feita por já existir no âmbito do laboratório executante (SIGEUrb/POLI/UFRJ) uma licença educacional que viabiliza também a atividade de pesquisa. Em face do pioneirismo desta pesquisa, demonstrado ao licenciador por meio de resultados preliminares, foi posteriormente obtida uma licença administrativa gratuita para a Prefeitura Universitária, o que garantirá a sequencia e aplicabilidade prática da pesquisa.

Foram então identificadas as fontes mais apropriadas e coletadas as informaçōes, grande parte ainda não georreferenciada e muito diversificada, como arquivos $\mathrm{CAD} / d w$, imagens de satélite, mapas e plantas em papel e alguns shapefiles desatualizados, demandando também uma criteriosa elaboração de metadados. Estas informaçôes foram entâo convertidas em imagens raster georeferenciadas, feiçōes geográficas e tabelas, todas ajustadas para ambos os sistemas geocêntricos (SIRGAS2000) e topocêntricos (SAD69), conferindo uma gama vasta para emprego futuro.

As feiçóes de polígonos foram utilizadas para representação de edificaçóes, quadras, estacionamentos e uso de solo, sendo inseridos os atributos que permitem a identificação institucional em vários níveis (Instituição, Centro, Unidade, etc.). A universidade já possui um sistema de gestáo acadêmica (SIGA) associado a uma base de dados contendo códigos de locais e instâncias, e está previsto um futuro módulo para geocodificaçấo, utilizando-a. As feições de polígonos podem ser visualizadas em cores sólidas, hachuras ou transparência, permitindo sua sobreposição às imagens de satélite e aerofotogrametria.

As feiçóes de linha foram utilizadas para representar os backbones das redes de abastecimento de água, esgoto sanitário, distribuição de energia, telecomunicaçóes e sistemas de transporte. Foram nelas incluídos atributos que permitem identificar o material, a dimensão e a carga destas redes. Também foram usadas linhas para representar a topografia e hidrografia, estas já ajustadas às cotas verticais. Estas linhas podem ser representadas por cores e espessuras distintas, que permitem a fácil visualização e identificação de seus elementos.

As feições de ponto foram empregadas para registrar os elementos componentes dos diversos sistemas e redes, como transformadores, registros, pontos de ônibus, etc. As feiçóes de ponto podem ser visualizadas através de simbologia adequada à sua representaçáo técnica.

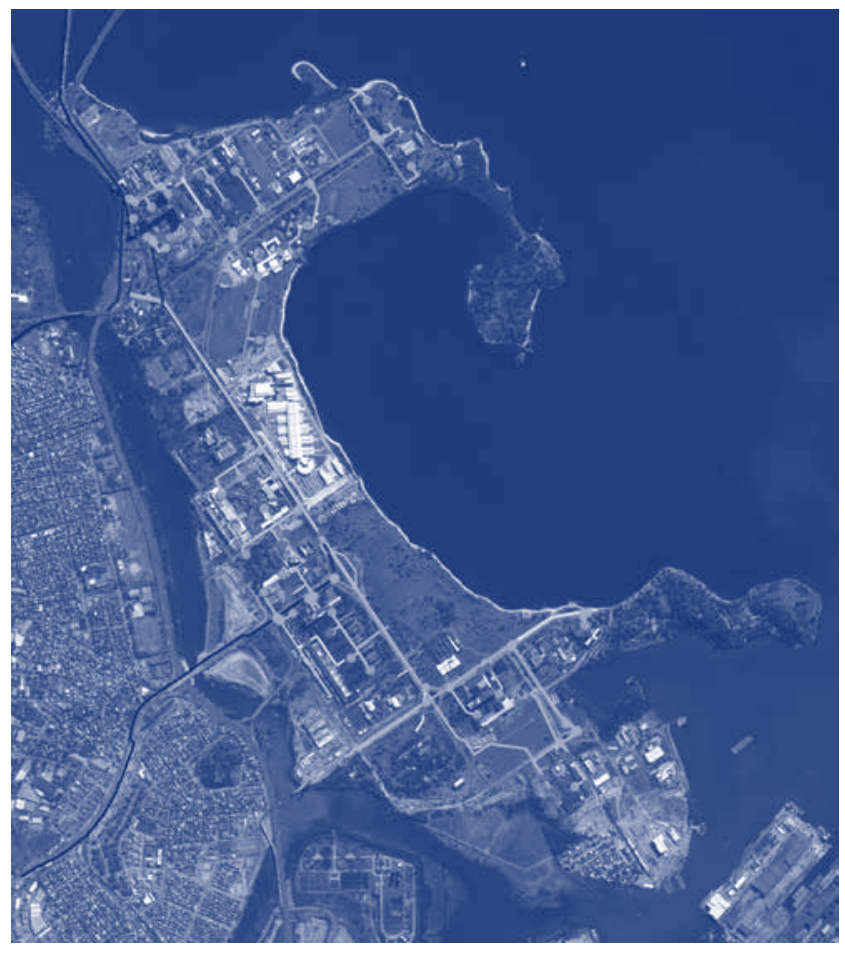

Figura 1: Rede de agua e imagem de satélite do campus implementados em um WebGIS. Fonte: Autores.

Estes pontos também podem ser inseridos a partir de dispositivos móveis (celular e ipad) facilitando a aquisição de dados em campo e em tempo real, como por exemplo, o registro de um acidente de trânsito ou um vazamento na tubulação de água.

Em seguida os dados foram integrados e adaptados às rotinas mais frequentes de um SIG. Dentre estas estão os módulos de agregação e extração de dados, consulta por SQL (Structured Query Language), visualização avançada, análise espacial e geração de mapas/relatórios. Também houve uma preocupação com outros aspectos operacionais, como flexibilidade de uso, compatibilidade de inputs e outputs, manutenção da base e atualizaçáo de dados.

O próximo passo será a validação da base de dados pelos agentes consultados na primeira etapa, seguida da implantaçáo em um WebSIG, para efeito de teste piloto, sendo que uma parte dos dados já se encontra implementada na plataforma Web ArcGIS OnLine (Figura 1).

Importante destacar que a escala em que os dados de SIG estáo produzidos é compatível com a de um bairro, ficando a escala da edificaçáo a cargo de outro projeto em paralelo, que esta mapeando todo o prédio do Centro de Tecnologia utilizando ambiente BIM e software Revit/Autodesk. A intenção é, em futuro bem próximo, pesquisar a integração destes dados através do software City Engine/ESRI, que se encontra em fase de licenciamento para nosso laboratório.

\section{Resultados}

No momento, a pesquisa já tem definida a forma de inserção e tratamento dos dados; os parâmetros operacionais tais como os sistemas de projeção, as simbologias e classificaçóes; a identificação 


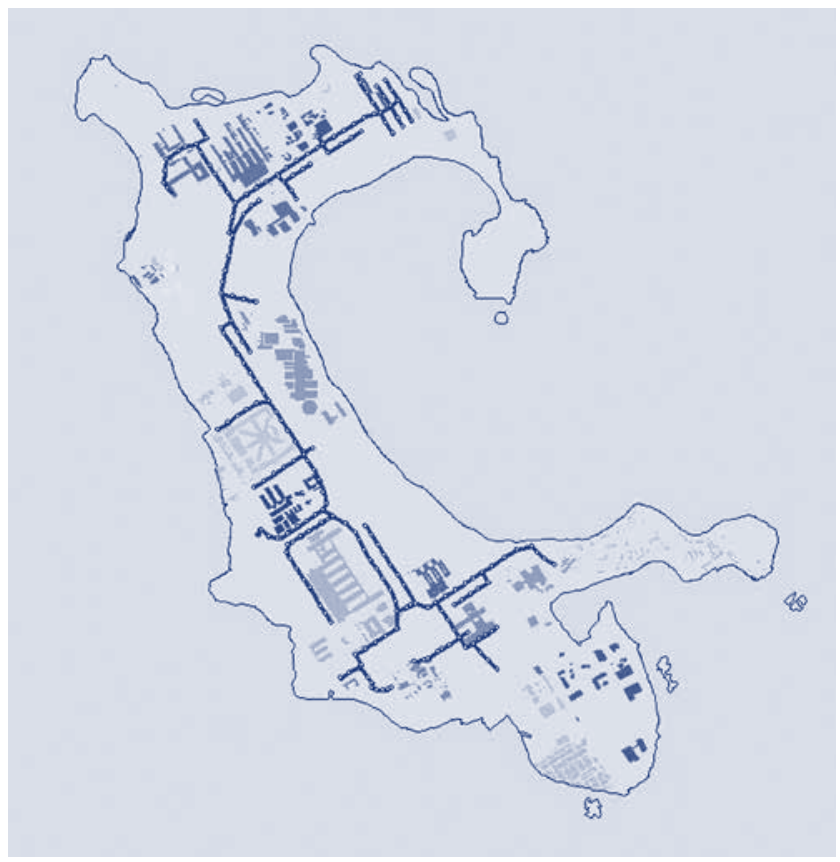

Figura 2: Sistema de esgoto sanitário e edificaçōes do campus. Fonte: Autores.

e coleta das informaçóes temáticas a serem consideradas no estudo; a abrangência e resolução dos temas; e as rotinas para visualização e produção dos mapas temáticos.

As informaçóes sobre sistema viário, edificaçóes e redes de água e esgoto (Figura 2) estão em fase final de revisão, e praticamente todas as definiçóes para sistemas de projeçáo, utilização de simbologia cartográfica e organização dos atributos em tabelas foram definidas. Porém nem todos os dados são acessíveis, pois no campo estão instaladas várias empresas e centros de pesquisa que ainda não disponibilizaram suas informaçóes.

Os dados já estão sendo produzidos de forma a serem posteriormente editados em SIG 3D, conforme alguns protótipos que já desenvolvemos com o software ArcScene/ESRI. Nestes protótipos elaboramos a modelagem 3D das edificaçóes e vias de transito, e geramos um modelo digital de terreno (DTM) a partir das curvas de nível (Figura 3).

Um elemento importante e que por vezes é descartado por compiladores quando transformam dados de CAD para SIG é a referência às cotas verticais. Esta informação permite restituir a altura efetiva da cobertura das edificações, eixos de rua e arruamentos, curvas de nível e hidrografia. Outros dados eventualmente dispensados sáo os pontos de levantamento topográfico. Todos estes elementos citados são importantes para a modelagem digital 3D e definição de suas geometrias e atributos. Citamos como exemplo a elaboração de uma geometria que represente a fachada de uma edificaçâo. Ao definirmos esta face como um polígono correspondendo a um registro próprio em uma tabela, poderão associar a ela outros atributos que permitirão simulaçóes, como índice de refletividade de material para estudos em acústica urbana.

A utilizaçáo de dados em 3D possibilitará, portanto, o desenvolvimento de novas utilidades para o sistema, como simular

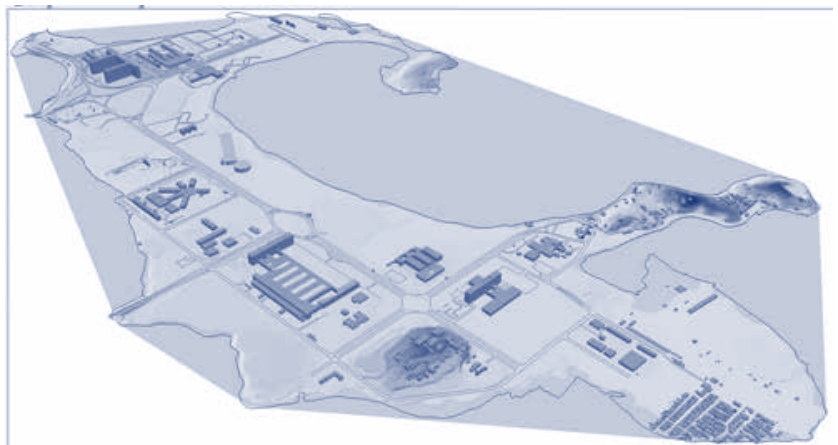

Figura 3: Modelo 3D do campus. Fonte: Autores.

condiçôes de conforto acústico e ambiental, e analisar consumo e desempenho de redes de energia, esgoto e água a partir da volumetria das edifcações. Também está prevista a integração com dados advindos da modelagem de edificaçóes do campus em ambiente BIM, produto de outra pesquisa que está sendo elaborada em paralelo. Uma vez implementado em WebSIG, espera-se que outros grupos de pesquisa possam desenvolver aplicativos em tecnologia mobile para registrar novos dados na base, em campo e em tempo real.

\section{Debate}

Muitas das açóes positivas em campus universitários deixam de ser conduzidas devido a dois principais fatores: a dificuldade em obter informaçóes atualizadas e a ausência de instrumentos formais para integração entre equipes. Nossa expectativa é de que, através da base de dados em SIG, os projetos locais envolvendo mobilidade, energia renovável e tecnologias urbano-prediais possam ser diretamente beneficiados, agregando inovação e sustentabilidade.

A universidade é por definição um vetor para gênese de ideias e soluçóes e, ao longo desta pesquisa, temos percebido a vontade de cada agente envolvido em ampliar a gama e escopo de suas açôes, e o mais importante: executá-las de forma mais integrada. Também merece atençáo o papel das universidades para a atividade de extensão, retornando para a sociedade que nela investe produtos e soluçóes que possam ser replicados no restante da cidade.

O SIG possibilita variadas formas de visualização, consulta e ediçâo dos dados nele inseridos, permitindo assim que o agente atuante em uma área tome ciência do todo, contribua de modo cognitivo com seus dados e se integre com os agentes de outras competências. Este viés de plataforma participativa é, em nossa opiniáo, a faceta mais importante do SIG aplicado à gestáo universitária.

Ao longo das etapas já cumpridas em nossa pesquisa detectamos uma grande dificuldade em obter dados concisos e atualizados, mas, por outro lado, não verificamos dificuldades técnicas maiores com o tratamento destes no ambiente SIG. O fato de termos na Engenharia uma disciplina de SIG também irá auxiliar no efeito multiplicador do emprego desta tecnologia dentro do campus, mobilizando alunos que desejem nesta tema se dedicar através de iniciação científica e estágio, dispositivo este já por nós efetivado nesta primeira fase do projeto. 
Embora os aspectos metodológicos estejam bem equacionados, podemos adiantar que o conhecimento factual do espaço físico do campus e a cognição das aplicações em ambiente SIG, assim como o bom relacionamento com os agentes detentores de informação, são fatores determinantes para o êxito da estruturaçáo dos dados e da modelagem gráfica digital.

\section{Agradecimentos}

Agradecemos à Prefeitura Universitária da UFRJ pelo apoio incondicional à nossa pesquisa, o fornecimento de dados e contribuição na revisão dos mesmos. Agradecemos também ao Departamento de Expressão Gráfica da POLI-UFRJ por compartilhar sua infraestrutura com o SIGEUrb, laboratório onde se desenvolve a pesquisa e que é vinculado ao Programa de Engenharia Urbana, possibilitando assim a realização de nossos trabalhos.

\section{Referências}

Abiko, A (2010). Urban Engineer Concepts and Challenges. In:Pina, A.C.F. e Pina A.C. Methods and techniques in urban Engineering. 1ed. Vukovar: In-Tech, v. 1. ISBN 978-953-307-096-4 Al-Rawabdeh , A., Al-Ansari, N., Attya, H., Knutsson, S (2014). GIS Applications for Building 3D Campus, Utilities and Implementation Mapping Aspects for University Planning Purposes. Journal of Civil Engineering and Architecture v8, n1, pags 19-28, 2014. ISSN 1934-7359

Cosenza C.A.N., Lima F. R., Neves C., (2010). Cap. 6- Research in Urban Engineering Applying Location Models. In: Armando
Carlos de Pina Filho, Aloisio Carlos de Pina. (Org.). Methods and Technics in Urban Engieering. 1ed. Vukovar: In-Tech, 2010, v. 1, ISBN 978-953-307-096-4

Couto, R.A.S. (2012) O uso de ferramentas georeferenciadas para o gerencimaneto de bens patrimoniais e prediais. Dissertação de Mestrado. FAU/USP.

Dailey, G., Stockton, S (2012). GIS in Education: Across Campuses, Inside Facilities ESRI E-books. Consultado em http:// www.esri.com/library/ebooks/gis-in-education-facilities.pdf

Konig, A. (2013). Regenerative sustainable development of univesities and cities. Cheltenham, UK: Edward Elgar Publishing Inc..

Lima F. R., Morel, G., Moraes, E. F. A. M. (2012). Portos e cidades: proposta para uma plataforma colaborativa no ambito da engenharia urbana, In: XIV Encontro Nacional de Tecnologia do Ambiente Construído, Juiz de Fora-MG. Anais do XIV ENTAC, 2012.

Hilton, B. N., Burkhard, R. J (2009).' Microenvironment Analysis of a University Campus: GIS Design Considerations for Process Repeatability Journal of Maps, Volume 5, Issue 1. DOI: 10.4113/jom.2009.1089

Ndunda, P (2005). Enterprise Campus GIS for the University of Redlands (Master's thesis, University of Redlands). Consultado em : http://inspire.redlands.edu/gis_gradproj/174

Walles, P. (2012). The Role of GIS Technology in Sustaining the Built Environment, ESRI E-books. Consultado em: http:// www.esri.com/library/ebooks/sustaining-the-built-environment.pdf 